\title{
B2C E-Commerce Logistics Network Optimization Model
}

Xiaheng Zhang, College of Business and Trade, Nanchang Institute of Science and Technology, China

\begin{abstract}
In this paper, considering the characteristics of e-commerce logistics and the problems arising from the construction of logistics network, based on the full investigation and research of the B2C electricity supplier operation mode, the author has studied and summarized the research results of scholars at home and abroad aiming at the related problems and summarized the methods and steps of logistics network optimization in the whole country. First, this article established the logistics network structure. The definition of network level, node function, and connection between nodes are carried out. Then, through the improved urban agglomeration order gravity model, the scope of selflogistics city is screened. Finally, the link of logistics network structure is scheduled for completion with the goal of cost optimization.
\end{abstract}

\section{KEYWORDS}

B2C Business, Logistics Network Optimization, Self-Logistics, Urban Agglomeration

\section{INTRODUCTION}

The e-commerce market in China is developing rapidly. As of the end of December 2012, the scale of online retail transactions in China's online retail market is 13030 billion yuan, an annual growth of $66.1 \%$. It accounts for more than $6.3 \%$ of the total retail sales of consumer goods. China's online shopping market has entered a relatively stable period of rapid growth. As an important part of the online retail market, the B2C market is showing a trend of competition. In 2012, the volume of transactions was 386 billion yuan, accounting for $29.6 \%$ of the total online shopping market, reflecting an increase of 4.3 percentage points compared with $25.3 \%$ in 2011. It has become the main driving force of the online shopping market. With the influx of large B2C companies, B2C retail will account for $75 \%$ of total retail sales by 2019 , and the B2C model has become a core component of online retail. After more than ten years of development, the online shopping market has begun to take shape, and the consumption concepts of Chinese online shopping consumers have changed. Consumers have a higher pursuit of product quality and service levels for online shopping, and the competitive strategy of e-commerce should also be changed (Biswas,2018; Ramakrishnan, 2010; Lu, 2010. Jiang, 2005; Zhang, 2007; Lee, 2001; Zhao,2003; Al-Momani, 2018; Grubljesic, 2019; Srinivasa, 2018; Reddy, 2018; Chang, 2019; Khatwani, 2018; Hamidi, 2018; Buckley, 2019; Liu, 2020).

In $\mathrm{B} 2 \mathrm{C}$ e-commerce companies, precision marketing strategies is the basic guarantee for the success of e-commerce companies. Using big data technology to process various types of customer data collected on the Internet, such as the conversion of unstructured data and the determination of data types and functions, etc., enterprises can grasp customer preferences, purchasing power, buying habits and purchasing intentions, in-depth understanding of customers and portraits. Companies formulate 
specific marketing plans based on customer portraits, effectively improve consumers' participation in corporate activities, establish a good brand image, and enhance customer loyalty to the company. Logistics distribution is a key link in the B2C e-commerce process. However, compared with the rapid development of network marketing in China, the distribution link in the e-commerce process is still disconnected from the sales link. In addition to the timely delivery of goods, such as door-todoor installation Customer satisfaction such as specific after-sales service is not high. At present, my country's logistics network cannot meet the precise marketing strategy of enterprises. Therefore, optimizing the logistics network is an important link for e-commerce companies to implement precision marketing strategies. In the era of big data, companies can make full use of various types of effective data information obtained on the Internet to formulate logistics distribution plans, and use data information to conduct effective analysis and research to achieve smart logistics. Improve the level of logistics services, reduce logistics costs, improve logistics efficiency, and achieve more sustainable development.

The optimization of B2C e-commerce self-distribution network is a problem with "Chinese characteristics". Restricted by the level of third-party logistics, B2C e-commerce companies in China must build their own logistics network in order to achieve efficient and accurate logistics distribution. The research of foreign scholars mostly focuses on the importance of logistics to e-commerce companies, mainly from the perspective of how logistics efficiency affects consumer spending habits. In recent years, domestic scholars have made definite progress on the location and path optimization of logistics networked nodes. Ramakrishnan Ramanathanl researches whether the timeliness of B2C e-commerce logistics and distribution will affect consumers' loyalty to B2C shopping websites by rating online customers and obtaining relevant data, and builds a consumer behavior analysis model on this basis. They also quantitatively calculated the impact of material flowed services on customer loyalty. Jiang Zhongzhong considers the cost of goods and assumes that B2C e-commerce companies choose one or more distribution center locations in the target area according to the demand and supply of the goods to minimize the total cost of the distribution system. The total cost include the supply cost of the goods provided by the supplier, the transportation cost from the supply point to the distribution center, the storage cost of the distribution center, the distribution and processing cost of the goods in the distribution center, and the distribution and transportation cost of the distribution center to the customer. A mixed 0-1 integer programming model for location selection of distribution centers is established. Huo Jiazhen selected economic development indicators, logistics infrastructure indicators, logistics industry performance indicators, energy consumption and environmental impact indicators, and safety indicators to establish a comprehensive evaluation index system for logistics center cities and quantify the comprehensive logistics strength of cities in the Yangtze River Delta, and established a multi-level distribution system (Fan,2004; Li,2011; Tan,2004; Ivanaj,2019; Wei,2019; Kim,2019; Bhadoria,2019; Kitouni,2018; Namasudra, 2018; Pham, 2019; Peng, 2019; Fabisiak, 2018; Parada, 2018; Singh, 2018; Shahri, 2019; Zhang, 2019).

\section{LOGISTICS NETWORK OPTIMIZATION MODE}

Logistics network planning is to determine the structure of the flow of products from the supply point to the demand point. The main focus of logistics network planning includes determining the appropriate number of warehouses, determining the location of each warehouse, determining the size of each warehouse, allocating product warehouse space, and providing customers with products in the warehouse (Figure 1).

In order to solve the common multi-facility location problem, a mixed integer programming model needs to be established.

The output of each supply factory does not exceed its production capacity.

Must satisfy all market demands.

The warehouse must have the lowest throughput before it can be operated. 
Figure 1. Generic structure of logistics network.

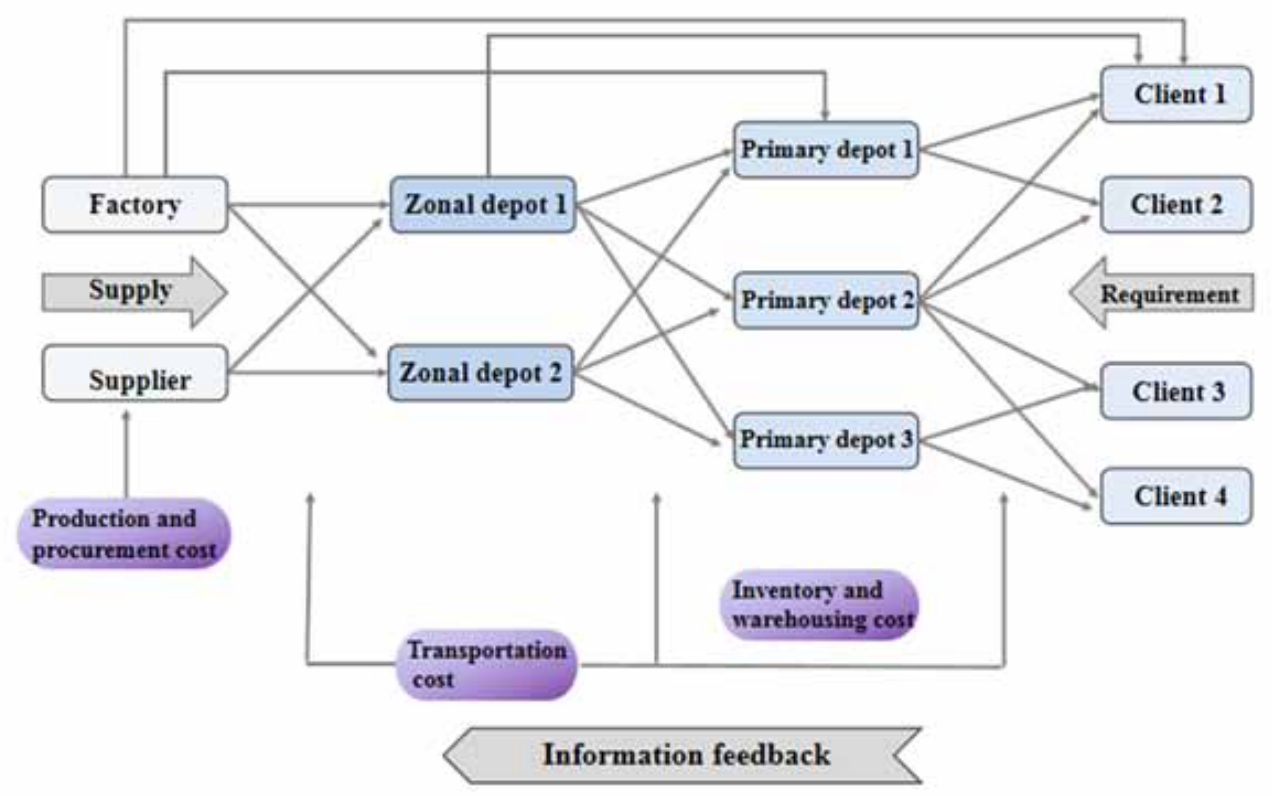

All products required for the same market must be supplied from the same warehouse.

After mastering the above data, the following results can be obtained by establishing and solving a mixed integer programming model.

The number, location and scale of warehouses in logistics network.

Which warehouse will be shipped to the factory?

What customer service is in the warehouse?

The logistics and transportation processes in the entire logistics system.

The current cost and total cost of logistics network.

The model established is usually:

$\operatorname{Min} C=\sum_{i j k} C_{i j k} X_{i j k}+\sum_{i k l} H_{k l} W_{i k l}+\sum_{k} f_{k} Z_{k}$

S.T.

$\sum_{k} X_{i j k} \leq M_{k} / /$ Factory capacity constraints (1).

$\sum_{j} X_{i j k}=\sum_{l} W_{i k l} / /$ Warehouse capacity limit (2).

$\sum_{l} W_{i k l}=D_{i l} Y_{k l} / /$ Meeting all customer needs (3).

$\sum_{k} Y_{k l}=1 / /$ Each customer can only be provided by one warehouse (4).

\section{B2C E-COMMERCE LOGISTICS NETWORK OPTIMIZATION KEY FACTORS}

From the point of view of business development, if the electricity giant only concentrates on a certain field, it is not difficult to fall into the "prisoner's dilemma" of the economy. Enterprises need to 
expand the types of product operations, break the prisoner's dilemma, and realize corporate profits. We need to consider factors such as the category of inventory products, the quantity of inventory products and so on, which are determined by the logistics attributes of products. Therefore, before carrying out the optimization of logistics network, we need to analyze the attributes of products and logistics and warehousing, determine the impact of these attributes on the function of logistics nodes, and determine the management strategy of the product in the logistics network.

\section{Selection of Commodity Attributes}

When choosing the attributes of commodities, we should choose the attributes that are related to the logistics indexes and affect the logistics indexes.

\section{Sales Volume of Commodities}

The index indicates that the sales volume of goods in the past time is a relative value, and can be set according to the " $20 / 80$ principle". $20 \%$ of all product categories have high sales, and the remaining part has low sales. The indicator shows the corresponding turnover rate of goods. Products with high sales have a relatively high turnover rate, and products with low sales have a relatively low turnover rate.

\section{Unit Price}

The index is the price of a single product, that is, the virtual value. The index reflects the amount of funds required to store such goods. The higher the unit price of the goods, the higher the amount of funds required.

\section{Profit Margin}

The indicator is the profit indicator of the product, and the relative value of the profit from the sales price. The higher the profit rate, the higher the overall profit rate ranking of the product, and the lower the profit rate after the ranking. The index reflects the profitability of the product, which is the main factor in choosing a market strategy. Profitability products with the same value are all profitable.

\section{Selection of Logistics Attributes}

When choosing logistics indicators, the factors we choose are functions of product attributes.

\section{Distribution Pattern}

The distribution pattern of products refers to which types of warehouses are stored in the goods. In this logistics network structure, there are two warehouses with stock holding functions, namely, regional distribution centers and front-end distribution centers. The number of regional distribution centers is small, the coverage is wide, and the product variety is large. The number of front-end distribution centers is considerable, the scale is relatively small, the coverage area is very compact, and the coverage type is not important. Accordingly, there are for two kinds of distribution patterns of commodities, which are centralized distribution, only holding stocks in the regional distribution centers. They are widely distributed in the regional distribution centers and the front end distribution centers. The advantage is that it is close to consumers and can achieve rapid response. However, the inventory cost is often higher in this mode, and centralized distribution can reduce inventory. However, in order to achieve the scale effect, the front-end distribution center is a transit point and the response speed is relatively slow. For commodities with high demand and turnover rate, they are widely distributed. For commodities with high profit margins, they are widely distributed, so as to achieve rapid market response and meet consumer needs. For high-priced commodities, centralized distribution is usually used to reduce management costs. 


\section{Inventory Quantity}

Inventory quantity refers to the daily inventory quantity of the product in the warehouse. High inventory can meet the needs of consumers, reduce the loss of customers due to shortage of goods, and can also attract potential customers who are lost due to shortage of goods from competitors. However, high inventory will inevitably bring the risk of cargo overstocks. This index is greatly affected by the commodity turnover rate and product prices. When the commodity turnover rate is low, the low inventory strategy is usually adopted. When the commodity price rises, the low inventory strategy is usually adopted. When the profit margin of the commodity is small, the low inventory strategy is adopted to reduce the risk of overstocking.

\section{Replenishment Frequency}

Replenishment frequency refers to the replenishment frequency of replenishing products, which is the inverse of the replenishment cycle. Increasing the frequency of replenishment can quickly respond to market demand. In the case of high-risk commodity demand and high turnover rate, low-frequency replenishment is often taken into account for its stability. When commodity profit margins are high, high-profit replenishment strategies are usually adopted.

\section{Logistics Network Management Method Selection}

After categorizing commodity attributes and combining the characteristics of logistics attribute, we select the best combination of logistics services to achieve high-quality logistics services and reduce logistics costs. Table 1 is the corresponding relationship between commodity and logistics network management method, and the logistics networks management method referred to in the table is the basic and universal condition. After certain product combinations, the choice of corresponding logistics attributes often has some conflicts. Therefore, after classifying the products, it is necessary to comprehensively consider the logistics network management method, so as to realize the complementarity of each logistics attribute and realize the overall optimization.

Product A has large sales, high prices and high profit margins. The logistics network strategy of wide distribution, high frequency replenishment and high inventory should be selected. For the star products of merchants with high sales volume and high profit margins, its warehouses are widely distributed, the inventory is high, and the risk of shortage is reduced, so that the market can respond quickly. But it was offset by two other factors, so we chose high inventory to assist the first stage to achieve market effect.

Product B has large sales, high prices and low profit margins. Generally, a logistics network strategy of wide-range distribution, high-frequency replenishment, and low inventory should be selected. Product attributes indicate that the product may be the main product of B2C merchants, and the product adopts a strategy of small profits but quick turnover to occupy the market. Therefore, this type of product should also be widely used because of its high price, low profit margin, high inventory risk, and high-frequency replenishment strategy is usually selected.

Product $\mathrm{C}$ has the characteristics of large output, low price, and high profit margin. The logistics network strategy with extensive distribution, high frequency replenishment and high inventory should be selected This type of product has always been a product with high sales and high profit margins. Although the price is low, the profit may not be as good as product A, but it is still a source of profit for $\mathrm{B} 2 \mathrm{C}$ companies, so the logistics network management method is the same as product $\mathrm{A}$.

Product D has high sales volume, low price and low profit margin. The logistics network strategy of wide distribution, low frequency replenishment and high inventory should be selected. This product features similar to product B, but its price is small. Therefore, we can meet market demand through high inventory, and reduce the costs of replenishment in the selection of logistics network strategy.

Product E has low volume, high price and high profitability. The logistics network strategy of centralized distribution, high-frequency replenishment and low inventory should be selected. This product is a potential product, which sales are low and the price is high. It should be centralized and 
Table 1. product categories corresponding to logistics network model

\begin{tabular}{|c|c|c|c|c|}
\hline $\begin{array}{l}\text { Product } \\
\text { Category }\end{array}$ & $\begin{array}{c}\text { Sales } \\
\text { Volume }\end{array}$ & Unit Price & $\begin{array}{l}\text { Profit } \\
\text { margin }\end{array}$ & Lodistics netwok magagement methods \\
\hline A & High & High & High & $\begin{array}{l}\text { Wide distribuution、 High frequency } \\
\text { replenishment, High inventory }\end{array}$ \\
\hline B & High & High & Low & $\begin{array}{l}\text { Wide distribuution, High frequency } \\
\text { replenishment, Low inventory }\end{array}$ \\
\hline C & High & Low & High & $\begin{array}{l}\text { Wide distribuution、 High frequency } \\
\text { replenishment, High inventory }\end{array}$ \\
\hline $\mathbf{D}$ & High & Low & Low & $\begin{array}{l}\text { Wide distribuution, Low frequency } \\
\text { replenishment, High inventory }\end{array}$ \\
\hline $\mathbf{E}$ & Low & High & High & $\begin{array}{l}\text { Concentrated distribuution, High frequency } \\
\text { replenishment, Low inventory }\end{array}$ \\
\hline $\mathbf{F}$ & Low & High & Low & $\begin{array}{l}\text { Concentrated distribuution, Low frequency } \\
\text { replenishment, Low inventory }\end{array}$ \\
\hline G & Low & Low & High & $\begin{array}{l}\text { Concentrated distribuution, Low frequency } \\
\text { replenishment, High inventory }\end{array}$ \\
\hline $\mathbf{H}$ & Low & Low & Low & $\begin{array}{l}\text { Concentrated distribuution, Low frequency } \\
\text { replenishment, Low inventory }\end{array}$ \\
\hline
\end{tabular}

distributed to reduce product management costs. At the same time, the product has a high price and high profit, which requires high-frequency replenishment to meet market demand as much as possible.

Product F is small in size, high in price, and low in profitability. We usually choose centralized distribution, low frequency replenishment, and low inventory as the logistics network strategy of product $\mathrm{F}$. This product has low sales volume, high price and low inventory. It should be distributed in a centralized manner. At the same time, its profit margin is extremely low, and low frequency replenishment strategy can be adopted.

Product $\mathrm{G}$ has low volume, low price and high profit rate. The logistics network strategy of centralized distribution, low frequency replenishment and high inventory should be selected. The features of product $\mathrm{G}$ are similar to products $\mathrm{E}$, which are potential products and usually choose centralized configuration. However, its price is quite low, so the strategy of high inventory and low replenishment can be adopted to complement each other's advantages and disadvantages.

Product $\mathrm{H}$ has the characteristics of low volume, low price and low profit. The logistics network strategy of centralized distribution, low frequency replenishment, and low inventory is usually adopted. Products with low sales and low profit margins should adopt a strategy of centralized distribution, low prices, low sales, and low frequency replenishment. B2C business market strategy and logistics strategy need to be adjusted for unusual situations. Due to the uncertainty and dynamism of the market environment, the classification of a commodity needs to be adjusted along with the market dynamics. Similarly, the corresponding logistics strategy needs to be adjusted regularly. Report to the adjustment cycle of product attribute classification, the adjustment cycle of logistics network management method can be relatively longer. 


\section{B2C ELECTRIC BUSINESS ENTERPRISE LOGISTICS NETWORK OPTIMIZATION OVERALL DESIGN}

\section{B2C E-Commerce Logistics Network Design Principles}

The basic principle of $\mathrm{B} 2 \mathrm{C}$ e-commerce logistics network design is to supplement user order requirements, while $\mathrm{B} 2 \mathrm{C} \mathrm{e}$-commerce logistics network optimization is to meet user order requirements and reduce logistics costs. The main content of logistics network design includes: network level sequence, node function definition, and node coverage. In the optimization of B2C e-commerce logistics network, it mainly reflects the three characteristics of the power supply industry:

Firstly, the distribution of demand is concentrated, which is positively correlated with the level of economic development. Online shopping develops gradually with the popularization of the Internet. Meanwhile, with the improvement of regional economic level, the demand of consumer for products also tends to be personalized and diversified. The emergence of e-commerce has met the needs of consumers.

Secondly, efficient logistics service is the basis of the operation of e-commerce. Therefore, effective logistics services are mainly aimed at the time limit and coverage of delivery. Timeliness of delivery requires e-commerce to establish warehouses nearby. However, China has abundant land resources. If warehouses are established at all demand points, it will cause inventory costs that almost every company cannot afford. So it needs to be divided at the network level.

Thirdly, logistics network is the carrier of ordering products. In order to meet the market's demand for multi-product products, while optimizing the logistics network and designing node functions, product attributes should be fully considered, and the functions of logistics nodes should be determined according to product attributes. Based on the analysis of the above problems, the three problems are combined to design the $\mathrm{B} 2 \mathrm{C}$ e-commerce self-service logistics network structure. A two-stage model is established, and combined with examples, a logistics network optimization solution is designed for B2C power suppliers under specific conditions.

\section{LOGISTICS NETWORK COST OPTIMIZATION MODEL AND ALGORITHM}

\section{Model Assumption}

The B2C e-commerce logistics network is designed based on the network structure and urban agglomeration distribution mode. The purpose is to clarify the functions of logistics nodes and complete the connection between nodes under the premise of cost inspection. The cost optimization model of the $\mathrm{B} 2 \mathrm{C}$ e-commerce logistics network is designed through the demand gravity model in the urban agglomeration distribution model to ensure the maximum order density. The definition of self-distribution city area was completed, and the center of the city group was selected. In this stage, the urban agglomeration center is seen as the FDC, and the urban nodes covered by the urban agglomeration are the urban nodes range covered by the FDC. All the FDC are selected as RDC alternative nodes to accomplish the connection design between RDC and FDC. In this stage, the cost is the best objective function. The optimization of logistics cost can be achieved. According to the above-mentioned logistics network topology, the self-logistics cost of B2C logistics network mainly includes: transportation cost $\mathrm{T}$, fixed asset lease and investment cost $\mathrm{W}$, and operating cost U. However, due to the limitation of logistics network structure, we need to achieve full coverage of $\mathrm{RDC}$ as much as possible, so we increase the service penalty cost $\mathrm{P}$.

An opportunity cost is utilized to set up the limiting conditions. When determining the cost, due to the different time attribute of each cost, the time dimension is needed to carry out the cost accounting. Transportation costs and operating costs are incurred every day, and part of the fixed asset costs can be converted into rental costs every day. The second part is the resultant fixed investment, which can calculate the amount of depreciation in a period of time. Therefore, we can choose the 
time length according to the strategic planning of the enterprise, and optimize the total cost of the logistics network by calculating the total cost in the time period.

(1) Orders are divided into two categories: I and II. I orders are low-volume products, usually using a centralized distribution model; II orders are large-volume products, using a wide-ranging distribution model. At the same time, the processing methods are different for different types of orders, as shown in Figure 2.

Figure 2. Different working flow of orders in the region.

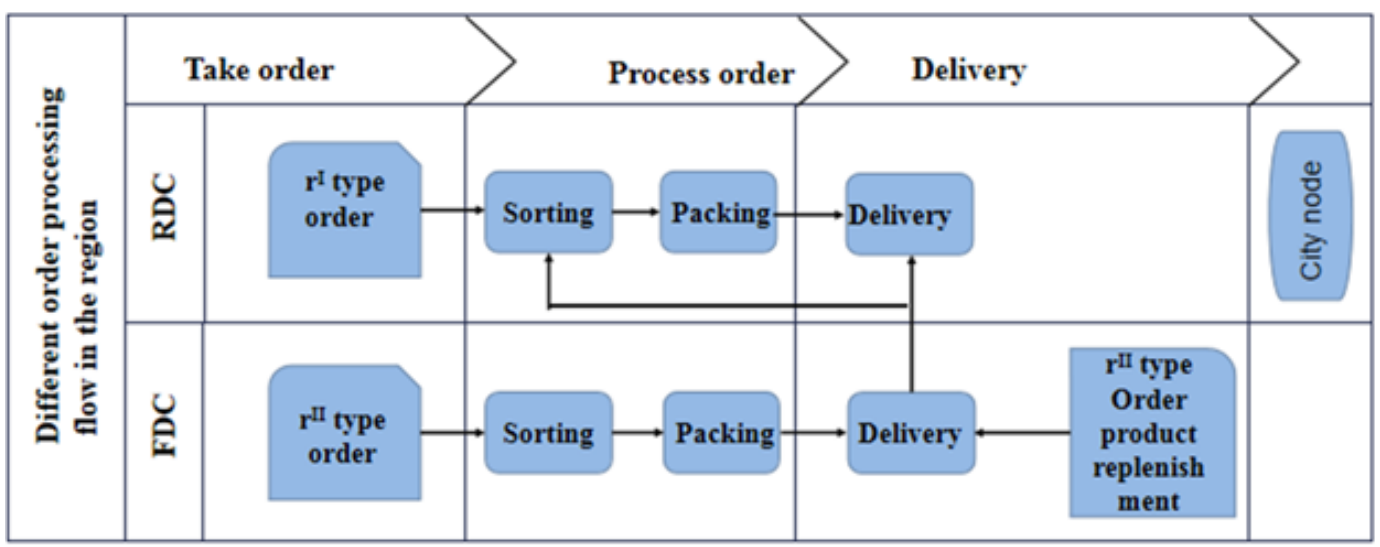

(2) The area of a regional distribution center is determined by the relevant functional requirements in operation. The order processing process is illustrated in the distribution center 3 . The regional distribution center mainly consists of a storage area, sorting area and outgoing area. The storage area is affected by product type, demand, product inventory and product order cycle. The sorting area and the outgoing area are mainly affected by product category and product demand (Figure 3).

(3) A day delivery from RDC to FDC.

(4) The order quantity is calculated in terms of days.

(5) FDC inventory is supplemented by RDC, and RDC to FDC replenishment products are shipped with other orders, no longer being distributed separately.

(6) In this model, the full load rate of vehicles is not considered, assuming that the capacity can meet the requirements.

(7) $\mathrm{T}$ is the time length of calculating cost in this model.

\section{Model Establishment}

In this model, the urban agglomeration centers obtained through the first stage of the model are set up as FDC. $\mathrm{M}\{\mathrm{m}, \mathrm{m}$.$\} , is the alternate node of RDC. In the second stage of cost optimization, FDC$ is classified and connected. The logistics costs considered in the model are mainly composed of the following four categories: transportation costs, fixed asset leasing and investment costs, operating costs and service penalty costs. Next, the four kinds of cost factors are analyzed and modeled in detail. Table 2 is the symbol definition appearing in the model. 
Figure 3. Order processing in distribution center.

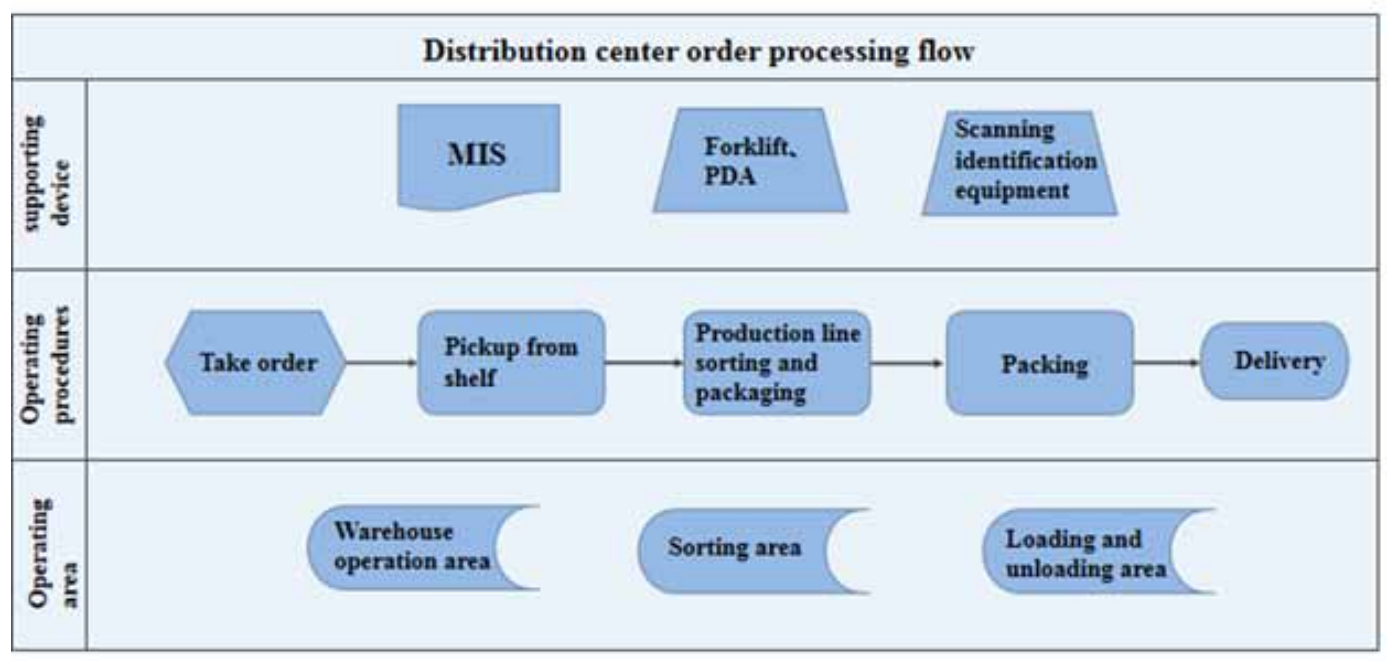

Table 2. symbols and their meanings

\begin{tabular}{|c|c|c|c|c|c|}
\hline Symbol & Meaning & Symbol & Meaning & Symbol & Meaning \\
\hline$M$ & Collectian of all rDC nedea & $h_{1}^{I} h_{1}^{I I}$ & Order Dal all erders I and II serrage ahare & $y_{l}$ & $\begin{array}{l}\text { The averaye praportion of ahchea storing gooda of } \\
\text { arder } 1 \text { Land area }\end{array}$ \\
\hline$m$ & rDC madc, belonpa to the callectien $\mathrm{DQ}$ & $\mu_{l}$ & $\begin{array}{l}\text { The east per unit kilameter of exch type } 1 \text { arder } \\
\text { trunk }\end{array}$ & $z_{l}$ & $\begin{array}{l}\text { The averaqe warchauac of the ahelves that store the } \\
\text { goeda of order } 1 \text { aterage arta }\end{array}$ \\
\hline$n$ & $\begin{array}{l}\text { The FDC node belonge to the set arlat } \\
\text { equal to } \mathrm{dO}\end{array}$ & $\delta_{m}$ & $\begin{array}{l}\text { Nade ags the } 0-1 \text { indiester of the regional } \\
\text { diatribution ectuter }\end{array}$ & $v_{l}$ & Redundaney factor af warchauac far order 1 \\
\hline$L$ & All erder types & $\omega_{m n}$ & 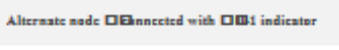 & $v_{l}$ & Warcheaning turnover rate of category 1 srder pooda \\
\hline$l$ & Order $\mathrm{T}_{y p}$ & $D_{m n}$ & Truak diatance of alternative nodes a & $\pi_{l}$ & Sarting, area required far catepory 1 ardern \\
\hline$I$ & Centrally dintributed prodect & $\sigma^{P}$ & $\begin{array}{l}\text { Ratio of mpplementary inventory tranupartation to } \\
\text { arder tranipartatiea rats }\end{array}$ & $\tau_{l}$ & Outbaund area required far catepory l arden \\
\hline$I I$ & Widely diatributsed preducts; & $\sigma^{P}$ & $\begin{array}{l}\text { Tnit area ratio of napplementary inveatory uorting } \\
\text { and order asting }\end{array}$ & $\varphi$ & $\begin{array}{l}\text { Redundansy factor af atarage in repianal diatribution } \\
\text { eenter }\end{array}$ \\
\hline$R_{m}$ & $\begin{array}{l}\text { VDC sade an } \\
\text { B2C online shapping ordern }\end{array}$ & $\sigma^{T o}$ & $\begin{array}{l}\text { Tnit area ratio of repleniahmeat inveatory outflew } \\
\text { and order outflow }\end{array}$ & $C^{1} C^{2} C^{3}$ & $\begin{array}{l}\text { RDC warchouns aperatien ares, artieg operation arca, } \\
\text { autbound operating arca leans cent per opeare meter } \\
\text { per day }\end{array}$ \\
\hline$\xi^{T}$ & Oac oyele time & $S_{m}^{1}$ & If पQ⿱一𫝀口DC, it in atorape arca & $C^{4}$ & $\begin{array}{l}\text { RDC warchouse renting ceat per aquare meter of land } \\
\text { per day }\end{array}$ \\
\hline$T$ & tranagortation cant & $S_{m}^{2}$ & If $\mathrm{Q} Q \mathrm{RDC}$, ith aertine packing area & $C_{\xi}^{s} T$ & $\begin{array}{l}\text { The fired injut cent af building }=\mathrm{RDC} \text { in in the } \mathrm{DB} \text {, } \\
\text { time periad diecouated price }\end{array}$ \\
\hline$W$ & Vixed auct lease and irveatment cants & $S_{m}^{3}$ & If $\mathrm{DQ}$ an DDC, ita eutbeund aperation arca & $k^{1} k^{2} k^{3}$ & $\begin{array}{l}\text { RDC warchouse apcratien arca, arting operatios arca, } \\
\text { autbaund operating cast per quare meter per day }\end{array}$ \\
\hline$U$ & Operating cant & $S_{m}^{4}$ & If $\mathrm{ag}$ RDC, the everall ares of it warchause & $k^{4}$ & $\begin{array}{l}\text { RDC warchouse daily aperatien and manapement cant } \\
\text { per aquare mettr af land }\end{array}$ \\
\hline$P$ & Peasalty cont & $x_{l}$ & $\begin{array}{l}\text { The averaye warchause required to camplete ench } \\
\text { categary larder arca }\end{array}$ & $\rho$ & $\begin{array}{l}\text { The pereentape of YDC arders lont when the penalty } \\
\text { exat ia taleulated }\end{array}$ \\
\hline$p$ & Averate pries of anline ahopping orden & $o_{m}$ & Serviee radian with $\mathbf{D Q g}$ the eenter of the arca & $\tau_{m n}$ & 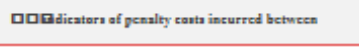 \\
\hline
\end{tabular}

\section{Transportation Cost}

In this stage, the transportation cost mainly includes the main line transportation cost of RDC-FDC and the transportation cost with road transportation as the main factor. It belongs to the path factor of the logistics system. Assuming that RDC-FDC realizes one-day delivery, the cost calculation in this stage can be simplified to calculate the transportation cost of each regional distribution center to transport orders and replenishment products to each front-end distribution center. The transportation cost of the order comes from the order generated by the goods stored in the RDC. Orders have been packaged 
uniformly and classified according to the size of the order and the transportation restrictions of the order. Therefore, the shipping rate for each online shopping order is different. The transportation cost of replenishment product inventory refers to the transportation cost arising from the replenishment of goods stored in FDC. These products are ultimately delivered from FDC to urban nodes in the form of orders. Due to the unified transportation of products, the transportation cost is lower than the order transportation rate. The shipment quantity from RDC to FDC can also be estimated based on the order quantity. The transportation cost coefficient represents the unit transportation cost of the product.

Transportation cost $=$ time period $\mathrm{x}$ (order transportation cost $/$ day + replenishment transportation cost / day).

$$
T=\xi^{T} \sum_{\substack{n=1 \\ n \neq m}}^{M} \sum_{l=1}^{L} \delta_{m} \omega_{m n} \mu_{l} D_{m n}\left(R_{n}^{I} h_{l}^{I}+R_{n}^{I I} h_{l}^{I I} \sigma^{T}\right)
$$

\section{Constraints:}

$\sum_{l=1}^{L} h_{l}^{I}=1, \sum_{l=1}^{L} h_{l}^{I I}=1$

$$
\left\{\begin{array}{l}
\sum_{\substack{m=1 \\
n \neq m}}^{M} \delta_{m} \omega_{m n} \leq 1, \text { if } \delta_{n}=0, \forall n \in M \\
\sum_{\substack{m=1 \\
m \neq n}}^{M} \delta_{m} \omega_{m n}=0, \text { if } \delta_{n}=1, \forall n \in M
\end{array}\right.
$$

The formula (6) indicates that the total value of orders for all types of orders is 1 , and the formula (7) indicates that each FDC is connected to a RDC at most.

\section{Fixed Assets Leasing and Investment Costs}

In the network structure, the fixed assets mainly include the warehouse rental cost, the rental cost of fixed assets related to the operation and other one-time fixed investment inputs. The warehouse rental cost is related to the warehouse area. The rental cost of the related fixed assets is related to the required product area of each function, and the warehouse area and the operation related area are determined by the number of orders. The rental cost can also be converted on a daily basis, and an one-time fixed investment can be converted into the depreciation amount over a period of time. Firstly, the warehouse area is calculated by the number of orders. The total storage area is mainly divided into the storage area, the sorting and packaging area, and the outbound operation area. RDC of the warehouse can be obtained by adding the area of each functional area, including the area of product category I and II: For category I, the need to cover all the orders in the area is required; For category II, in addition to covering the city cluster where it is located, it also needs to cover the order demand generated by other front-end distribution centers in the area. In other words, its area covers the replenishment demand of FDC. In the formula, the commodities of category II are also simplified to all order need. The formula for calculating the area of storage operations is shown in formula 8 .

$S_{m}^{1}=\sum_{l=1}^{L} \frac{\delta_{m} h_{l} x_{l} y_{l}\left[R_{m}^{I} h_{l}^{I}+R_{m}^{I I} h_{l}^{I I}+\sum_{\substack{n=1 \\ n \neq m}}^{M} \omega_{m n}\left(R_{n}^{I} h_{l}^{I}+R_{n}^{I I} h_{l}^{I I}\right)\right]}{\vartheta_{l} v_{l} z_{l}}$ 
The sorting area of RDC is directly proportional to the number of daily order sorting. The total RDC order area is calculated through the total amount of orders in the area, which requires sorting I type orders and II orders of its own city group. For Class II orders of the city clusters in the coverage area, due to the overall sorting, the sorting area of each product is smaller than the order sorting area. The coefficient $P$ is added in the calculation, as shown in formula 9:

$$
S_{m}^{2}=\sum_{l=1}^{L} \delta_{m} \pi_{l}\left(R_{m}^{I} h_{l}^{I}+R_{m}^{I I} h_{l}^{I I}+\sum_{\substack{n=1 \\ n \neq m}}^{M} \omega_{m n} R_{n}^{I} h_{l}^{I}+\sum_{\substack{n=1 \\ n \neq m}}^{M} \omega_{m n} R_{n}^{I I} h_{l}^{I I} \sigma^{P}\right)
$$

The outgoing operation area of RDC achieves the order of packing, and the order is calculated by setting the coefficient, that is, the order flow rate of the output area per square meter. Similarly, due to the overall scale effect of the replenishment products, the required area of the unit product is relatively small, and its coefficient of addition T0, as shown in formula 10:

$$
S_{m}^{3}=\sum_{l=1}^{L} \delta_{m} \tau_{l}\left(R_{m}^{I} h_{l}^{I}+R_{m}^{I I} h_{l}^{I I}+\sum_{\substack{n=1 \\ n \neq m}}^{M} \omega_{m n} R_{n}^{I} h_{l}^{I}+\sum_{\substack{n=1 \\ n \neq m}}^{M} \omega_{m n} R_{n}^{I I} h_{l}^{I I} \sigma^{T O}\right)
$$

The total area of B2C logistics regional distribution center can be obtained, as shown in formula 11:

$$
S_{m}=\frac{S_{m}^{1}+S_{m}^{2}+S_{m}^{3}}{\phi}
$$

After calculating the operation area of each operation area, the total warehouse cost of the regional distribution center can be calculated. The concrete expression is shown in formula 12.

$$
W=\sum_{m=1}^{M} \delta_{m}\left[\xi^{T}\left(C^{1} S_{m}^{1}+C^{2} S_{m}^{2}+C^{3} S_{m}^{3}+C^{4} S_{m}^{4}\right)+C_{\xi^{T}}^{5}\right]
$$

\section{Operation Cost}

The maintenance cost of the $\mathrm{B} 2 \mathrm{C}$ business logistics system mainly includes the daily operating costs of RDC. According to the area of RDC storage area, sorting area and outbound operation area, the daily operating costs of these three parts are obtained, and the management cost is calculated according to the total area occupied by RDC. At last, the daily cost of operation and maintenance of RDC can be obtained by integrating the above four fees. The concrete expression is shown in formula 13.

$$
U=\xi^{T} \sum_{m=1}^{M} \delta_{m}\left(k^{1} S_{m}^{1}+k^{2} S_{m}^{2}+k^{3} S_{m}^{3}+k^{4} S_{m}^{4}\right)
$$

\section{Cost of Service Penalty}

In order to satisfy the service quality and timeliness of logistics at the same time, the logistics network and logistics network design of B2C e-commerce need to achieve complete coverage in the area as much as possible and calculate the penalty cost when the logistics service timeliness cannot be achieved. The service penalty cost can quantify the service level of B2C e-commerce logistics 
system. The order valued calculation of customer churns caused by the lack of service due to the lack of service. If the distance between the FDC of a certain area and its RDC is larger than the service radius of RDC, then the penalty is imposed, and the service penalty rate is set to the average value of the order. Then the value of the service penalty cost is the total value of the order reduction of the FDC node online shopping. The order lost in the cost of its service penalty is only the order type II of the urban group, which is not covered. Its specific expression is shown in formula 14:

$$
\begin{gathered}
P=\sum_{m=1}^{M} \sum_{\substack{n=1 \\
n \neq m}}^{M} \delta_{m} \omega_{m n} \tau_{m n} \rho p R_{n}^{I I} \\
\tau_{m n}=\left\{\begin{array}{l}
0, d_{m n} \leq o_{m}, \forall m, n \in M \\
1, d_{m n}>o_{m}, \forall m, n \in M
\end{array}\right.
\end{gathered}
$$

The formula 15 represents the judgment of whether the FDC node is the service penalty cost. If and only when FDC is connected to a regional center and the RDC radius of the area is longer than the radius of the RDC pair, the value will take the 1. Ensemble mentioned above. When the cost factor of the overall system reaches the minimum, the overall model of the second stage of the best. B2C e-commerce logistics network optimization scheme of RDC is as follows:

$$
\operatorname{Min} Z_{2}=T+W+U+P
$$

S.T.

$$
\begin{aligned}
& \sum_{l=1}^{L} h_{l}^{I}=1, \sum_{l=1}^{L} h_{l}^{I I}=1 \\
& \left\{\begin{array}{l}
\sum_{\substack{m=1 \\
n \neq m}}^{M} \delta_{m} \omega_{m n} \leq 1, \text { if } \delta_{n}=0, \forall n \in M \\
\sum_{\substack{m=1 \\
n \neq m}}^{M} \delta_{m} \omega_{m n}=0, \text { if } \delta_{n}=1, \forall n \in M
\end{array}\right. \\
& \tau_{m n}=\left\{\begin{array}{l}
0, D_{m n} \leq o_{m}, \forall m, n \in M \\
1, D_{m n}>o_{m}, \forall m, n \in M
\end{array}\right.
\end{aligned}
$$

The formula 16 indicates that the minimum sum of transportation cost, fixed assets lease and investment cost, operation cost and service penalty cost is the objective function. The formula 17 indicates that the sum of the order type ratio is 1 . The formula 18 indicates that the center of each city group is connected to the center of one region, and the regional center is not connected. The formula 19 indicates that the service penalty is generated when the connection distance exceeds the service radius of the regional center.

\section{Algorithm and Example Analysis}

\section{Algorithm Analysis}

Because of the diversity of products, there are many variables and constraints in the $\mathrm{B} 2 \mathrm{C}$ business enterprise. So the model is a mixed 0-1 integer programming. It belongs to NP-hard problem. This paper adopts a genetic algorithm to solve the problem.

\section{Chromosome Coding}

In this paper, we adopt the integer coding strategy of mixed natural numbers. The basic idea is to use $\mathrm{L}$ (I-K) natural number to represent RDC, to numbered FDC numbers into one row, and to express connection by numbers in $\mathrm{L}(\mathrm{I}-\mathrm{K})$. For example, $\mathrm{L}=4$ and FDC have 8.

The corresponding FDC code is as follows: 
$[2,1,4,4,1,3,2,3]$

$[1,2,3,4,5,6,7,8]$

This part of the encoding constitutes the tail part of the chromosome. The first row is encoded as a FDC connection, indicating that there are $4 \mathrm{RDC}$ advanced nodes. The first advanced node is connected to FDC No. 2 and No. 5, the second advanced node is connected to FDC No. 1 and No. 7, and the third advanced node is connected No. 6 and No. 8 FDC, the fourth advanced node is connected to No. 3 and No. 4 FDC.

$[1,2,3,4 \mid 2,1,4,4,1,3,2,3]$

$[1,2,3,4 \mid 1,2,3,4,5,6,7,8]$

\section{Population Regeneration}

Setting the crossover operator can control the speed at which the population produces new individuals. Since the first segment of the chromosome only serves as an indicator, the mutation operation is only performed on the second segment of the chromosome. For example, two chromosomes are $\mathrm{A}=[1$, $2,3,4 \mid 2,1,4,3,1,4,2,3], \mathrm{B}=[1,2,3,4 \mid 2,2,1,3,1,3,2,4]$, and two chromosomes after crossing become $\mathrm{A}=[1,2,3,4 \mid 2,1,4,3,1,3,2,4], \mathrm{B}=[1,2,3,4 \mid 2,2,1,3,1,4,2,3]$, realized the exchange of FDC points connected by RDC.

\section{Algorithm Convergence and Parameter Self-Control}

In view of the premature feature of the genetic algorithm, the idea of simulated annealing is introduced to extend its fitness. The parent $p_{1}$ and $p_{2}$ are cross-operate to get the children $c_{1}$ and $c_{2}$. Calculate the fitness $\mathrm{F}\left(p_{1}\right), \mathrm{F}\left(p_{2}\right), \mathrm{F}\left(c_{1}\right)$, and $\mathrm{F}\left(c_{2}\right)$ of $p_{1}, p_{2}, c_{1}, c_{2}$ respectively. If we meet the requirement of $\mathrm{F}$ $\left(c_{1}\right)<\mathrm{F}\left(p_{1}\right)$ and $\mathrm{F}\left(c_{2}\right)<\mathrm{F}\left(p_{2}\right)$, we will use the sum of squares and squares instead of the squares. Otherwise, with probability $\exp \left(-\frac{f\left(c_{1}\right)-f\left(p_{1}\right)}{\tau}\right)$ and $\exp \left(-\frac{f\left(c_{2}\right)-f\left(p_{2}\right)}{\tau}\right), c_{1}$ and $c_{2}$ are accepted respectively, and the formula of $\mathrm{T}$ in probability is:

$T=T_{0} a^{K}(20)$

$a$--The constant between $[0,1] ; K$--The number of iterations.

The parameters are changed in an adaptive way, and the parameters are re-selected according to the condition of the chromosome. If the convergence speed is too slow, reduce the population size $\mathrm{M}$ according to the step size $k$. Local convergence is generated, and the mutation rate and crossover rate are changed according to step $\mathrm{f}$ and $\mathrm{q}$, and the first step is implemented. If local convergence occurs, the crossover rate changes to $\mathrm{p}+\mathrm{q}$, considering the change of crossover rate to jump out of local convergence in time. We use step size change to increase the crossover rate. When the initial crossover rate is $\mathrm{p} O$ and the step length is $\mathrm{h} O$ the crossover rate will change to $\mathrm{p} l=\mathrm{p} O h O$ In the new round iteration of the new crossover rate $\mathrm{p} l$ If $\mathrm{Zn}_{e w}>Z o_{l d}$ is found, it will increase no effect: we use the opposite step size change, namely $\mathrm{p} i=p 0 h 0$ If $\mathrm{Zn}_{\mathrm{ew}}<\mathrm{Zo}$ ld accept the new step length, and generate new adaptability at the same time. Otherwise, it shows that the single step $\mathrm{h} O$ is not ideal: $\mathrm{h} l_{=} 2 \mathrm{~h} O_{h}$ makes the new step size transformation, and the same step size is used for the mutation rate to get the best mutation rate and crossover rate on the basis of a RDC selection scheme, so as to get the best adaptability.

\section{Termination Criteria}

When the maximum number of iterations is reached and the algorithm temperature falls to the termination temperature or the fitness change meets the termination condition, the termination algorithm outputs the optimal solution (Figure 4). 
Figure 4. Algorithm structure frame.

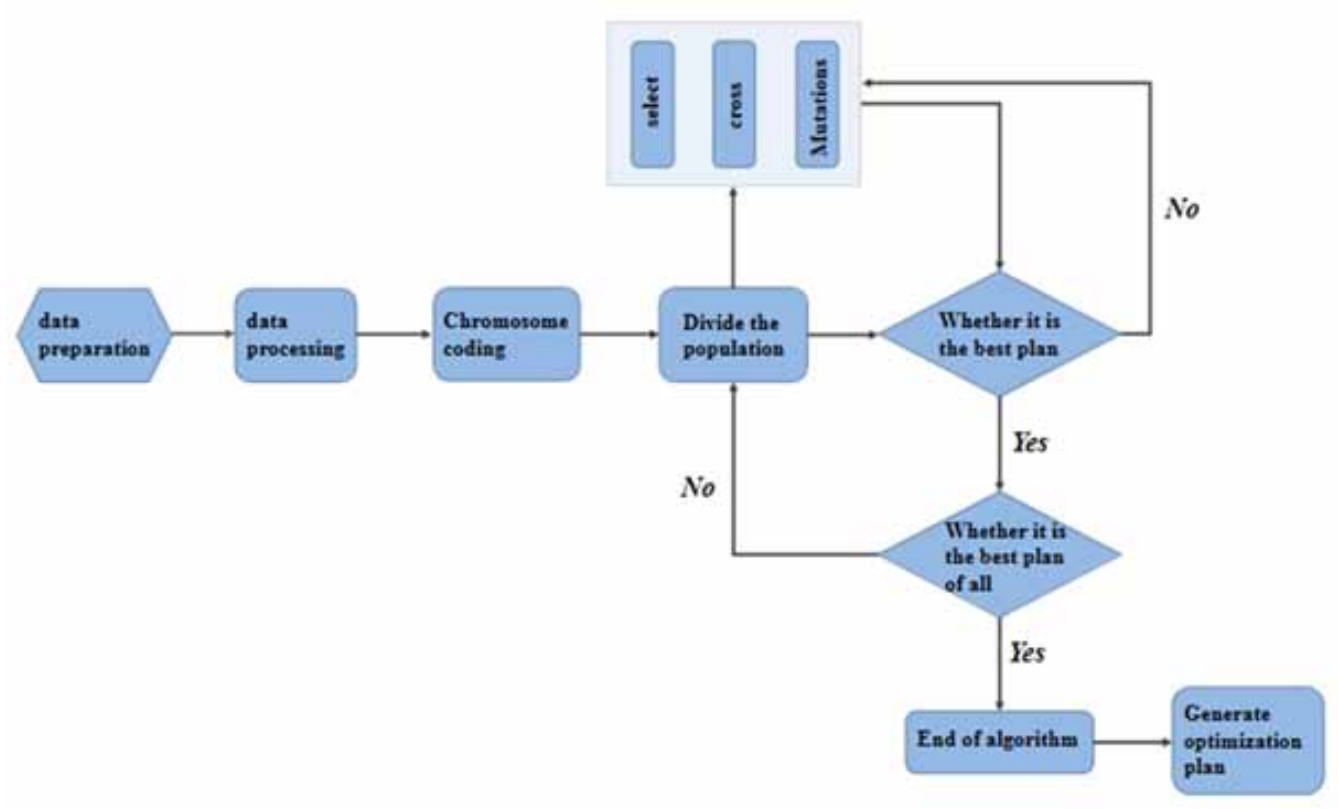

\section{Example Analysis}

On the basis of the last chapter, a logistics network optimization cost model is established based on 13 urban agglomerations as FDC nodes and RDC nodes. In this model, 5 RDC are built, covering 13 urban agglomeration centers, and the concrete results are shown in Figure 5 and Table 3.

In the two stage, the structure and level of logistics network in the whole country are shown in Table 4.

The results obtained by solving the two-stage model may be different from the actual situation. It is because the quantitative analysis of the model has strong characteristics. In the B2C network decision-making process, it is necessary not only to carry out quantitative analysis, but also to make qualitative adjustments according to its characteristics and strategic development direction. 


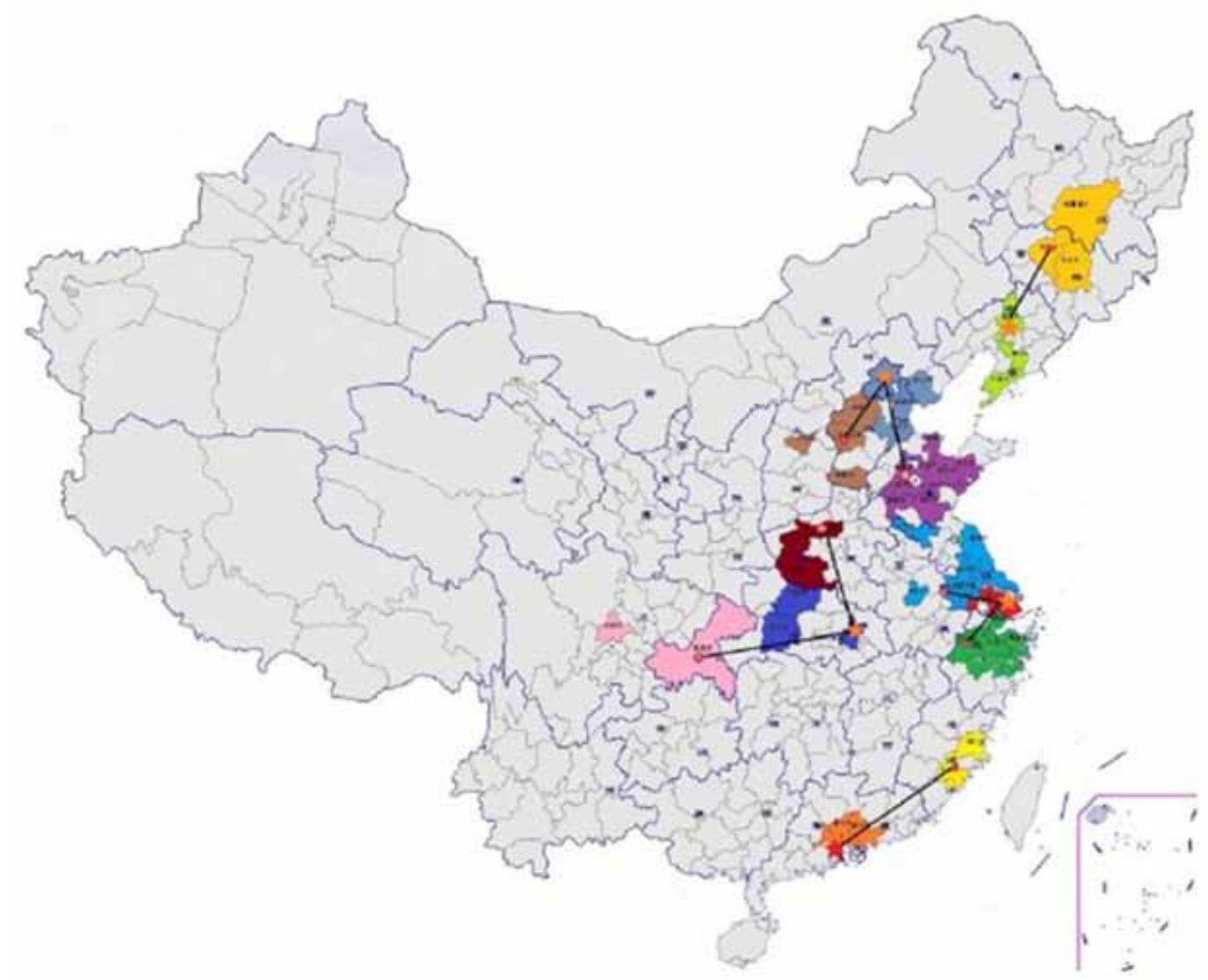

Table 3. result of the location and cover ranger of RDCs

\begin{tabular}{l|l}
\multicolumn{1}{c|}{$\begin{array}{c}\text { Regional } \\
\text { Distribution } \\
\text { Center }\end{array}$} & \multicolumn{1}{|c}{ Coverage } \\
\hline Shenyang & Changchun \\
Beijing & Shijiazhuang、Jinan \\
Wuhan & Zhengzhou、Chongqing \\
Shanghai & Nanjing、Hangzhou \\
Guangzhou & Fuzhou \\
\hline
\end{tabular}


Table 4. logistics network of B2C E-commerce in China

\begin{tabular}{|c|c|c|}
\hline $\begin{array}{l}\text { Regional } \\
\text { Distribution } \\
\text { Center }\end{array}$ & $\begin{array}{l}\text { Front-end } \\
\text { distribution center }\end{array}$ & City node: \\
\hline \multirow{2}{*}{ Shenyang } & Changcbun & Changchun, Jilin, Haerbin \\
\hline & Sheayang & Shenyang. Anshan. Dalian \\
\hline \multirow{3}{*}{ Beijing } & Beijing & Bejing. Tianjin, Tangshan, Cangzhou \\
\hline & Shijiazhuang & Shijiazhuang. Baoding. Handan, Taiyuan \\
\hline & Jinan & Jinan, Zibo, Weifang, Jining, Linyi, Dongying. Taian, Qingdao \\
\hline \multirow{3}{*}{ Wuhan } & Zhengzhou & Zhengzhou, Luoyang. Nanyang \\
\hline & Waken & Wuhan, Xiangyang. Yichang \\
\hline & Chongegiag & Chongqing. Chengdu \\
\hline \multirow{3}{*}{ Shanghai } & Shanghai & Shanghai, Wuxi, Suzhou \\
\hline & Nanjing & $\begin{array}{l}\text { Nanjing, Nantong. Changzhou, Hefei, Yancheng. Yangzhou, Taizbou, Zhenjiang. } \\
\text { Xuzhou }\end{array}$ \\
\hline & Hangrhou & Hangzhou, Ningbe, Shaoxing, Jinxing. Taizhou, Jinhun \\
\hline \multirow{2}{*}{ Guangzhou } & Furhou & Fuzhou, Quaszhou, Xiamen \\
\hline & Guangzhou & Guangzhou, Shenzhen, Foshan, Dongguan, Zhongshan, Huizhou \\
\hline
\end{tabular}

\section{CONCLUSION}

Precision marketing strategy is the foundation for the sustainable development of e-commerce companies. This marketing method can significantly enhance the sales capabilities of the company and enhance customer loyalty to the brand. The establishment of a smart logistics network in e-commerce is the basis for a company to carry out precision marketing strategies. The model is constructing and solving on the basis of in-depth understanding of the internal demand of enterprises, based on the current logistics network optimization of B2C e-commerce self-logistics. The construction of a logistics network is based on certain assumptions, focusing on the design and calculation of a series of models around the number of orders. With the development of B2C e-commerce logistics, the logistics network structure will become more complex, and the problems that need to be solved and faced will appear one after another. We will briefly elaborate on the problems that can be further explored in the future. In short, with the development of China's e-commerce, the expansion of the product category will inevitably lead to the diversification of logistics mode, and the material flow network will be more complex. The research on logistics network will also be more in-depth and practical. It is hoped that the research of e-commerce and logistics in China will guide the development direction of e-commerce logistics in the future.

\section{ACKNOWLEDGMENT}

The study was supported by Jiangxi Provincial Department of Education Science and technology research project "Jiangxi Province cross border e-commerce industry chain cluster research" (GJJ202505); Talents research project of Nanchang Institute of Science and Technology "Research on the whole industrial chain agglomeration of cross border e-commerce" (ngrczx-20-11). 


\section{REFERENCES}

Al-Momani, A. M., Mahmoud, M. A., \& Ahmad, M. S. (2018). Factors that influence the acceptance of internet of things services by customers of telecommunication companies in Jordan. Journal of Organizational and End User Computing, 30(4), 51-63. doi:10.4018/JOEUC.2018100104

Bhadoria, R. S., \& Chaudhari, N. S. (2019). Pragmatic sensory data semantics with service-oriented computing. Journal of Organizational and End User Computing, 31(2), 22-36. doi:10.4018/JOEUC.2019040102

Biswas, S., Devi, D., \& Chakraborty, M. (2018). A hybrid case based reasoning model for classification in internet of things (Iot) environment. Journal of Organizational and End User Computing, 30(4), $104-122$. doi:10.4018/JOEUC.2018100107

Buckley, P., Noonan, S., Geary, C., Mackessy, T., \& Nagle, E. (2019). An empirical study of gamification frameworks. Journal of Organizational and End User Computing, 31(1), 22-38. doi:10.4018/JOEUC.2019010102

Chang, K. C., \& Seow, Y. M. (2019). Protective measures and security policy non-compliance intention: IT vision conflict as a moderator. Journal of Organizational and End User Computing, 31(1), 1-21. doi:10.4018/ JOEUC.2019010101

Fabisiak, L. (2018). Web service usability analysis based on user preferences. Journal of Organizational and End User Computing, 30(4), 1-13. 10.4018/JOEUC.2018100101

Fan, Y. J. (2004). Analysis of logistics bottlenecks in the development of e-commerce. Business Times., 22(17), 51-52.

Grubljesic, T., Coelho, P. S., \& Jaklic, J. (2019). The shift to socio-organizational drivers of business intelligence and analytics acceptance. Journal of Organizational and End User Computing, 31(2), 37-64. doi:10.4018/ JOEUC. 2019040103

Hamidi, H., \& Jahanshahifard, M. (2018). The role of the internet of things in the improvement and expansion of business. Journal of Organizational and End User Computing, 30(3), 24-44. doi:10.4018/JOEUC.2018070102

Ivanaj, S., Nganmini, G. B., \& Antoine, A. (2019). Measuring e-learners' perceptions of service quality. Journal of Organizational and End User Computing, 31(2), 83-104. doi:10.4018/JOEUC.2019040105

Jiang, Z. Z., \& Wang, D. W. (2005). Model and algorithm of location optimization of distribution center in B2C e-commerce. Control and Decision., 20(10), 1125-1128.

Khatwani, G., \& Srivastava, P. R. (2018). Impact of information technology on information search channel selection for consumers. Journal of Organizational and End User Computing, 30(3), 63-80. doi:10.4018/ JOEUC.2018070104

Kim, H. (2019). Investigating the mediating role of social networking service usage on the big five personality traits and on the job satisfaction of Korean workers. Journal of Organizational and End User Computing, 31(1), 110-123. doi:10.4018/JOEUC.2019010106

Kitouni, I., Benmerzoug, D., \& Lezzar, F. (2018). Smart agricultural enterprise system based on integration of internet of things and agent technology. Journal of Organizational and End User Computing, 30(4), 64-82. doi:10.4018/JOEUC.2018100105

Lee, H. L., \& Whang, S. (2001). Winning the last mile of e-commerce. MIT Sloan Management Review, 42(4), 54-62.

Li, Z. F. (2011). Discussion on the relationship between enterprise logistics management and e-commerce. Modern Business., 12(18), 10-11.

Liu, J., Zhou, Y., Jiang, X., \& Zhang, W. (2020). Consumers' satisfaction factors mining and sentiment analysis of B2C online pharmacy reviews. BMC Medical Informatics and Decision Making, 20(194), 194. Advance online publication. doi:10.1186/s12911-020-01214-x PMID:32807175

Lu, Y. B., Zhao, L., \& Wang, B. (2010). From virtual community members to C2C e-commerce buyers: Trust in virtual communities and its effect on consumers' purchase intention. Electronic Commerce Research and Applications, 9(4), 346-360. doi:10.1016/j.elerap.2009.07.003 
Namasudra, S., \& Roy, P. (2018). PpBAC: Popularity based access control model for cloud computing. Journal of Organizational and End User Computing, 30(4), 14-31. doi:10.4018/JOEUC.2018100102

Parada, R., Melia-Segui, J., \& Pous, R. (2018). Anomaly detection using rfid-based information management in an Iot context. Journal of Organizational and End User Computing, 30(3), 1-23. doi:10.4018/JOEUC.2018070101

Peng, J. P., Quan, J., \& Peng, L. (2019). IT application maturity, management institutional capability and process management capability. Journal of Organizational and End User Computing, 31(1), 61-85. doi:10.4018/ JOEUC.2019010104

Pham, L. M. T., Tran, L. T. T., Thipwong, P., \& Huang, W. T. (2019). Dynamic capability and organizational performance: Is social networking site a missing link? Journal of Organizational and End User Computing, 31(2), 1-21. doi:10.4018/JOEUC.2019040101

Ramakrishnan, R. (2010). The moderating roles of risk and efficiency on there relationship between logistics performance and customer loyalty in e-commerce. Transportation Research Part E, Logistics and Transportation Review, 950-962.

Reddy, M. R., Srinivasa, K. G., \& Reddy, B. E. (2018). Smart vehicular system based on the internet of things. Journal of Organizational and End User Computing, 30(3), 45-62. doi:10.4018/JOEUC.2018070103

Shahri, A., Hosseini, M., Phalp, K., Taylor, J., \& Ali, R. (2019). How to engineer gamification: The consensus, the best practice and the grey areas. Journal of Organizational and End User Computing, 31(1), 39-60. doi:10.4018/ JOEUC.2019010103

Singh, P., \& Agrawal, R. (2018). A customer centric best connected channel model for heterogeneous and Iot networks. Journal of Organizational and End User Computing, 30(4), 32-50. doi:10.4018/JOEUC.2018100103

Srinivasa, K. G., Sowmya, B. J., Shikhar, A., Utkarsha, R., \& Singh, A. (2018). Data analytics assisted internet of things towards building intelligent healthcare monitoring systems: Iot for healthcare. Journal of Organizational and End User Computing, 30(4), 83-103. doi:10.4018/JOEUC.2018100106

Tan, Q. M., \& Wang, Z. L. (2004). A study on the role of urban logistics in pulling economy 1 . Take Nanjing, Jiangsu as an example. Industrial Technology and Economy., 23(1), 89-91.

Wei, C. L., \& Ho, C. T. (2019). Exploring signaling roles of service providers' reputation and competence in influencing perceptions of service quality and outsourcing intentions. Journal of Organizational and End User Computing, 31(1), 86-109. doi:10.4018/JOEUC.2019010105

Zhang, L. X. Z., Mouritsen, M., \& Miller, J. R. (2019). Role of perceived value in acceptance of "Bring your own device" policy. Journal of Organizational and End User Computing, 31(2), 65-82. doi:10.4018/ JOEUC.2019040104

Zhang, S. X., \& Huo, J. Z. (2007). Research on the planning of multi-tier city logistics distribution system in the Yangtze River Delta. Science and Technology Progress and Countermeasures., 24(6), 50-53.

Zhao, G. J., \& Li, H. (2003). The impact of e-commerce on logistics development. Journal of Beijing University of Posts and Telecommunications, 4(4), 26-30. 


\section{ENDNOTES}

${ }^{1}$ Xiaheng Zhang (1982-), male, Han nationality, Jining, Shandong, PhD, associate professor, main research directions: e-commerce.He is the Corresponding Author ,the email :zhangxiaheng@nwupl.edu.cn. 